\title{
Four Fallacies and an Oversight: Searching for Martian Life
}

\author{
J.D. Rummel ${ }^{1}$ and C.A. Conley ${ }^{2}$
}

\begin{abstract}
While it is anticipated that future human missions to Mars will increase the amount of biological and organic contamination that might be distributed on that planet, robotic missions continue to grow in capability and complexity, requiring precautions to be taken now to protect Mars, and particularly areas of Mars that might be Special Regions. Such precautionary cleanliness requirements for spacecraft have evolved over the course of the space age, as we have learned more about planetary environments, and are the subject of regular deliberations and decisions sponsored by the Committee on Space Research (COSPAR). COSPAR's planetary protection policy is maintained as an international consensus standard for spacecraft cleanliness that is recognized by the United Nations Committee on the Peaceful Uses of Outer Space. In response to the paper presented in this issue by Fairén et al. (2017), we examine both their concept of evidence for possible life on Mars and their logic in recommending that spacecraft cleanliness requirements be relaxed to access Special Regions "before it is too late." We find that there are shortcomings in their plans to look for evidence of life on Mars, that they do not support their contention that appropriate levels of spacecraft cleanliness are unaffordable, that there are major risks in assuming martian life could be identified by nucleic acid sequence comparison (especially if those sequences are obtained from a Special Region contaminated with Earth life), and that the authors do not justify their contention that exploration with dirty robots, now, is preferable to the possibility that later contamination will be spread by human exploration. We also note that the potential effects of contaminating resources and environments essential to future human occupants of Mars are both significant and not addressed by Fairén et al. (2017). Key Words: Mars—Special Region—Mission—Life detection—Planetary protection. Astrobiology 17, 971-974.
\end{abstract}

\section{Introduction}

T HERE IS A FUNDAMENTAL consensus within the Mars exploration community ( $c f$. Rummel et al., 2014), presented in the paper accompanying this one, with which we heartily agree:

human arrival will inevitably increase the introduction of terrestrial and organic contaminants. And that could jeopardize the identification of indigenous martian life. (Fairén et al., 2017)

We are also pleased to find that Fairén et al. (2017) join the Mars community in endorsing the concept of Mars "Special Regions," which plays a key role in protecting astrobiology on the planet via implementation of the planetary protection policy promulgated by the Committee on Space Research (COSPAR) of the International Council for Science. The current COSPAR Planetary Protection Policy defines Mars Special Regions as locations in which Earth life could propagate-where the temperature is at or above $-28^{\circ} \mathrm{C}$ and water activity is at least 0.5 ( $c f$. Kminek and Rummel, 2015; Kminek et al., 2016). ${ }^{1}$ Though a Mars Special Region may also be defined as a place known to host martian life, there are currently no parameters explicitly defining such a place (Kminek and Rummel, 2015).

There is significant heritage behind the current COSPAR policy, the origin of which dates back to the late $1950 \mathrm{~s}$. COSPAR regularly studies new ways to explore our solar system while not contaminating it and provides an opportunity for the widest possible exchange of views on the subject (see Kminek and Fisk, 2017, in this issue). In

\footnotetext{
${ }^{1}$ The history of the concept of Special Regions and recommended updates since 2011 are summarized in Rettberg et al. (2016) and links therein, and subsequent recommendations for modifications to the COSPAR policy, accepted by the COSPAR Bureau in March, 2017, are given in Kminek et al. (2016).
}

\footnotetext{
${ }^{1}$ SETI Institute, Mountain View, California.

${ }^{2}$ NASA Headquarters, Washington, DC.
}

(C) J.D. Rummel and C.A. Conley, 2017; Published by Mary Ann Liebert, Inc. This Open Access article is distributed under the terms of the Creative Commons Attribution Noncommercial License (http://creativecommons.org/licenses/by-nc/4.0/) which permits any noncommercial use, distribution, and reproduction in any medium, provided the original author(s) and the source are credited. 
addition to providing scientific guidance, the 2017 UN Committee on the Peaceful Uses of Outer Space recognized

the long-standing role of COSPAR in maintaining the planetary protection policy as a reference standard for spacefaring nations and in guiding compliance with article IX of the Outer Space Treaty (UN OOSA A/72/20, 2017)

This is a significant responsibility, and one only needs to read the COSPAR policy to understand why. Fairén et al. (2017) posit that the advent of humans on Mars would mean "Planetary protection policies as we conceive them today will no longer be valid." Yet this concern is not supported by the current COSPAR Planetary Protection Policy, which has been central in efforts to protect against the backward contamination of Earth since the Apollo missions of the late 1960s, and has included explicit principles and guidelines relating to human Mars missions since 2008 (Kminek and Rummel, 2015).

Despite the fundamental acceptance by Fairén et al. (2017) of the key concerns regarding human exploration and an endorsement of the COSPAR Mars Special Region concept, the messages of their accompanying article are decidedly mixed. The sum of the arguments made by Fairén et al. (2017) to relax planetary protection requirements seems to be that it would be advantageous to contaminate Special Regions with robots, now, so that humans won't get to be the first to do it later.

In this paper, we address four fallacies inherent in the arguments made by Fairén et al. (2017) with regard to planetary protection requirements applied to Mars exploration, as follows: (1) the contention that evidence of martian life would best be found in Special Regions is not well supported; (2) evidence and cost estimations based on real mission systems suggest that cleaning robotic missions to currently required levels is in fact not a significant impediment to accessing candidate Special Regions; (3) the claim that martian life could convincingly be identified by nucleic acid sequence comparison, if it were obtained from a Special Region contaminated with Earth life, is invalidated by recent evidence of highly divergent life on Earth; and (4) the idea that exploration with dirty robots is urgent because human exploration is imminent seems to ignore the possibility that contamination from poorly prepared robotic missions could spread as easily as contamination associated with human missions.

Note that, to address these fallacies concretely, we cite them as they have been presented in Fairén et al. (2017).

As to the "oversight" noted in our title, Fairén et al. (2017) failed to acknowledge the possibility that introduced Earth organisms could cause damage both to martian resources we hope will be available to future human explorers and-considering that many Earth organisms are facultative pathogens (e.g., Clostridium tetani) - potentially to the explorers themselves.

\section{Are Special Regions the Best Places to Search for Martian Life?}

Fairén et al. (2017) state that "when new missions are designed to incorporate a true life-searching payload ... they do not include among their objectives the exploration of the 'Special Regions.', However, access to Special Regions is not considered a high priority objective by the scientific community (Committee on the Planetary Science Decadal Survey, 2012). As noted above, Special Regions are defined as loca- tions that potentially could provide habitats for Earth life, based on observed capabilities of Earth organisms. Claims that reducing planetary protection requirements wouldn't be harmful, because Earth life can't grow on Mars, may be reassuring as opinion, but the facts are that we keep discovering life growing in extreme conditions on Earth that resemble conditions on Mars. We also keep discovering conditions on Mars that are more similar - though perhaps only at microbial scales-to inhabited environments on Earth, which is where the concept of Special Regions initially came from (e.g., Beaty et al., 2006; Rummel et al., 2014).

One challenge for mission development is that no confirmed Special Regions have yet been shown to exist on Mars. There are features considered to be candidate Special Regions, but some previous candidates have been discarded (e.g., most gullies), and the best of the candidates currently under consideration would be unreachable with current mission capabilities (e.g., deep subsurface aquifers). Recurring slope lineae (RSL) are a favored candidate to some, and Fairén et al. (2017) make a point of noting that RSL form "arguably as a result of contemporary water activity," though they also cite the work of Edwards and Piqueux (2016), which suggests that RSL are effectively dry (under 3\% water) and might not be optimal places to find martian life today.

A much greater challenge for accessing RSL than planetary protection is that they are found on slopes-often $45^{\circ}$ or more-which means that in order to study them, the challenges of trafficability will be critical. It has been proposed to send the Curiosity rover, itself not cleaned to levels required for Special Regions access, to nearby candidate RSL features in Gale Crater. The possibility that the rover could break through a salt crust or tumble down a slope, or both, is of concern for planetary protection because a sunken or crashed rover with its own heat source could release Earth microbes into a locally warm, and possibly wet, martian environment. It is probable that a mission-ending accident would be of concern to rover operators for other reasons as well.

The programmatic emphasis of the Mars exploration programs of both NASA and ESA has been explicitly to focus on investigating sites of ancient habitability, for example, locations showing evidence that liquid water was persistent in the past, because that's where Mars life is likely to have been most abundant (see Committee on the Planetary Science Decadal Survey, 2012). Accordingly, and irrespective of planetary protection considerations, there is no consensus within the Mars community for conducting missions that might detect extant martian life. Although Levin and Straat (2016) still contend that the Viking labeled release experiment found life on Mars, the Mars community is not convinced that a mission to attempt (re?)detection of extant martian life is a high priority. If scientists wish to propose such a mission, they must first advocate successfully for one as a matter of scientific priority. That advocacy should include considering whether a Special Region, if found, would be the right place for such a mission to go.

\section{Is It Prohibitively Expensive to Clean Spacecraft to the Levels Required for Special Regions Access?}

If it is critical for a life-detection mission to investigate a place on Mars most likely to host Earth life, then eliminating Earth organisms from spacecraft hardware to 
prevent their growth and subsequent detection would be a sensible precaution.

Claims that planetary protection implementations are "cost-prohibitive" don't usually address the question of planetary protection costs in detail but simply state that costs "can substantially increase" if one goes to a Special Region ( $c f$. Fairén and Schulze-Makuch, 2013). The oftrepeated estimate of " $10 \%$ of total mission cost" for the planetary protection project for Viking included the cost of ground-based infrastructure, while the two most expensive science instruments on Viking were $20 \%$ of the total mission cost (Bionetics Corporation, 1988); thus, planetary protection total costs were equivalent to that of one large science instrument. A thorough Jet Propulsion Laboratory study (Gavit et al., 2006) put the recurring costs of sending Viking-level-sterilized Mars Exploration Rovers to Mars at about $14 \%$ above non-sterilized-rover costs, including reserves. When one considers that each Mars Exploration Rover cost less than a new Boeing 747, this is not a huge amount of money-certainly not enough to prohibit doing a proper job of searching for life on Mars by ensuring we don't instead find the Earth life we brought with us.

\section{Can Nucleic Acid Sequence Comparison Distinguish Definitively between Martian and Earth Life?}

There is a very real possibility that extraterrestrial life does not possess either RNA or DNA, which would make any question of sequence comparison irrelevant. Nonetheless, Fairén et al. (2017) have argued that sequence relatedness could be used to discern the difference between Earth contamination and martian life with certainty, for example:

As it is expected that the RNA/DNA sequence of any potential martian microorganisms will be significantly different from any organism on Earth, indigenous martian microbes might form a new kingdom or subkingdom at the very base of the bacteria or archaea branches of the universal tree of life.

The premise is that sequence data would show martian life (if it exists) to be "deeply branched" because transfers of material from Earth to Mars are infrequent, though this fails to consider the implications of the easier trip from Mars to Earth, which happens 10 times more frequently (Mileikowsky et al., 2000). Regardless of the potential for twoway exchange, the contention that martian life would be easily recognized is falsified by multiple observations, including those cited by Fairén et al. (2017).

New groups of Bacteria and Archaea that have been discovered within the past several years (e.g., Hug et al., 2016) are "deeply branched" relative to the tree of life as it has previously been understood. What if we had found these organisms on Mars prior to 2010? Or what if we have found other new groups of deeply branching organisms in samples of martian material? How could we tell whether, in either case, they represent martian organisms or previously unrecognized Earth contaminants?

\section{Why Should Robots Be Allowed to Contaminate Mars before Humans Get There?}

An apparent objective behind two papers on this topic (Fairén and Schulze-Makuch, 2013; Fairén et al., 2017) is to convince readers that relaxing cleanliness requirements on robotic missions is necessary to reduce the expense of discovering life on Mars, before humans arrive, because humans will spread Earth microbial contamination and make it impossible to recognize martian life. This advocacy neglects the likelihood that robotic missions will create similar problems, themselves, if they are also spreading Earth microbial contamination. There already is Earth life on Mars because our robots on Mars contain viable Earth organisms, but this doesn't mean we'd be happy to find them again.

Fairén et al. (2017) make the case for urgency in exploring Mars Special Regions because "plans are being drafted to send humans to Mars during the 2030 decade, both from international space agencies and the private sector." It should be noted that NASA has been drafting plans to bring samples from Mars to Earth since the 1970s, before the end of the Viking Program. A human mission to Mars is NASA's stated "horizon goal," but this is not the same as a serious programmatic commitment - with an accepted rationale, budget, and schedule. To date, no government agency has produced such a commitment, and the details of private initiatives are still more hopeful than convincing. There is still time to explore Mars properly.

Without careful contamination control, however, robotic life-detection instruments could obtain a false positive or equivocal detection of life on Mars; in fact, the SAM instrument on Curiosity has already detected Earth contamination at levels that swamp out possible signals from Mars (Freissinet et al., 2015). If an astronaut exploring Mars is likely to run into martian organisms, that fact should be well understood before landing there. Inadvertent exposure might affect astronaut health and their permission to return to Earth. Exposure to unknown Earth organisms could be a source of confusion in that circumstance.

\section{An Oversight: What about the Fact That Earth Organisms Can Be Harmful?}

Given the assumption that there really will be a serious effort to go to Mars with humans and have them do things on the surface, we can posit that human missions will inevitably bring a large population of Earth microbes along with them. We should anticipate, too, that not all of those microbes will always be harmless. If humans are going to contaminate Mars, we also need to be concerned about the possibility that the microbes they carry could endanger the astronauts, both in their native state and if they mutate in the space environment. If Earth life and martian life are related, or if martian life is unrelated but still uses DNA/RNA, then lateral gene transfer is another route for acquiring new (and potentially hazardous) traits. While COSPAR planetary protection policies are principally science-enabling, they have other benefits as well.

A new pathogen is only one concern. Others are more mundane. For example, introduced Earth microbes could prevent the use of existing resources on, or under, the surface of Mars. We don't have a good understanding of where, and in what form, those resources will be discovered; but if something like an underground aquifer is contaminated by Earth organisms, it is clear that it could quickly be made less useful by the Earth organisms released into it. In particular, certain Earth organisms introduced into an underground environment could behave like the self-calcifying crack-closing microbes discovered, and used as a concrete additive, by some clever researchers at the Delft University of Technology (Jonkers et al., 2010). 


\section{Summary}

It is important that missions looking for indigenous life on Mars do so with the most effective contamination control measures available. For science to succeed, shortcuts should be scrutinized mercilessly. If we intend to live on Mars one day, the integrity of our efforts, now, will be a critical contribution to the future of humans on Mars. Advocating for unjustified loosening of bioburden controls translates into doing a poor job of life detection and forward contamination control during the robotic exploration of Mars. Such an approach is self-limiting and does nothing for future human exploration. Doing so without an informed understanding of the real costs and what is at risk would be ignorant and irresponsible.

\section{Acknowledgment}

The authors want to thank Sherry Cady for her efforts to provide through this journal a forum for all things astrobiological, including the question of how best to search for life on Mars.

\section{References}

Beaty, D., Buxbaum, K., Meyer, M., Barlow, N., Boynton, W., Clark, B., Deming, J., Doran, P.T., Edgett, K., Hancock, S., Head, J., Hecht, M., Hipkin, V., Kieft, T., Mancinelli, R., McDonald, E., McKay, C., Mellon, M., Newsom, H., Ori, G., Paige, D., Schuerger, A.C., Sogin, M., Spry, J.A., Steele, A., Tanaka, K., and Voytek, M. (2006) Findings of the Mars Special Regions Science Analysis Group. Astrobiology 6:677-732.

Bionetics Corporation. (1988) Lessons Learned from the Viking Planetary Quarantine and Contamination Control Experience, contract NASW-4355, the Bionetics Corporation, Hampton, VA.

Committee on the Planetary Science Decadal Survey. (2012) Vision and Voyages for Planetary Science in the Decade 2013-2022, National Academies Press, Washington, DC.

Edwards, C.S. and Piqueux, S. (2016) The water content of recurring slope lineae on Mars. Geophys Res Lett 43:8912-8919.

Fairén, A.G. and Schulze-Makuch, D. (2013) The overprotection of Mars. Nat Geosci 6:510-511.

Fairén, A.G., Parro, V., Schulze-Makuch, D., and Whyte, L. (2017) Searching for life on Mars before it is too late. Astrobiology 17, doi:10.1089/ast.2017.1703.

Freissinet, C., Glavin, D.P., Mahaffy, P.R., Miller, K.E., Eigenbrode, J.L., Summons, R.E., Brunner, A.E., Buch, A., Szopa, C., Archer, P.D., Jr., Franz, H.B., Atreya, S.K., Brinckerhoff, W.B., Cabane, M., Coll, P., Conrad, P.G., Des Marais, D.J., Dworkin, J.P., Fairén, A.G., François, P., Grotzinger, J.P., Kashyap, S., ten Kate, I.L., Leshin, L.A., Malespin, C.A., Martin, M.G., Martin-Torres, J.F., McAdam, A.C., Ming, D.W., Navarro-González, R., Pavlov, A.A., Prats, B.D., Squyres, S.W., Steele, A., Stern, J.C., Sumner, D.Y., Sutter, B., Zorzano, M.-P., and the MSL Science Team. (2015) Organic molecules in the Sheepbed Mudstone, Gale Crater, Mars. J Geophys Res: Planets 120:495-514.

Gavit, S., Allestad, D., Gerke, D., Hill, J., and McClure, S., for the MSS Study Team. (2006) Mars System Sterilization Study Report, JPL-D-34992 produced under Contract Number NAS7-03001, Task Order 10805. Jet Propulsion Laboratory, Pasadena, CA.

Hug, L.A., Baker, B.J., Anantharaman, K., Brown, C.T., Probst, A.J., Castelle, C.J., Butterfield, C.N., Hernsdorf, A.W., Amano, Y., Ise, K., Suzuki, Y., Dudek, N., Relman, D.A.,
Finstad, K.M., Amundson, R., Thomas, B.C., and Banfield, J.F. (2016) A new view of the tree of life. Nat Microbiol 1, doi:10.1038/nmicrobiol.2016.48.

Jonkers, H.M., Thijssen, A., Muyzer, G., Copuroglu, O., and Schlangen, E. (2010) Application of bacteria as self-healing agent for the development of sustainable concrete. Ecol Eng 36:230-235.

Kminek, G. and Fisk, L.A. (2017) Protecting our investment in the exploration and utilization of space. Astrobiology 17, doi:10.1089/ast.2017.1748.

Kminek, G. and Rummel, J.D. (2015) COSPAR's Planetary Protection Policy. Space Research Today 193:7-19.

Kminek, G., Hipkin, V.J., Anesio, A.M., Barengoltz, J., Boston, P.J., Clark, B.C., Conley, C.A., Coustenis, A., Detsis, E., Doran, P., Grasset, O., Hand, K., Hajime, Y., Hauber, E., Kolmasová, I., Lindberg, R.E., Meyer, M., Raulin, F., Reitz, G., Rennó, N.O., Rettberg, P., Rummel, J.D., Saunders, M.P., Schwehm, G., Sherwood, B., Smith, D.H., Stabekis, P.E., and Vago, J. (2016) COSPAR Panel on Planetary Protection colloquium, Bern, Switzerland, September 2015 (Meeting Reports). Space Research Today 195:42-67.

Levin, G.V. and Straat, P.A. (2016) The case for extant life on Mars and its possible detection by the Viking labeled release experiment. Astrobiology 16:798-810.

Mileikowsky, C., Cucinotta, F.A., Wilson, J.W., Gladman, B., Horneck, G., Lindegren, L., Melosh, J., Rickman, H., Valtonen, M., and Zheng, J.Q. (2000) Natural transfer of viable microbes in space: 1. From Mars to Earth and Earth to Mars. Icarus 145:391-427.

Rettberg, P., Anesio, A.M., Baker, V.R., Baross, J.A., Cady, S.L., Detsis, E., Foreman, C.M., Hauber, E., Ori, G.G., Pearce, D.A., Renno, N.O., Ruvkun, G., Sattler, B., Saunders, M.P., Smith, D.H., Wagner, D., and Westall, F. (2016) Planetary protection and Mars Special Regions-a suggestion for updating the definition. Astrobiology 16:119-125.

Rummel, J.D., Beaty, D.W., Jones, M.A., Bakermans, C., Barlow, N.G., Boston, P.J., Chevrier, V.F., Clark, B.C., de Vera, J.P., Gough, R.V., Hallsworth, J.E., Head, J.W., Hipkin, V.J., Kieft, T.L., McEwen, A.S., Mellon, M.T., Mikucki, J.A., Nicholson, W.L., Omelon, C.R., Peterson, R., Roden, E.E., Sherwood Lollar, B., Tanaka, K.L., Viola, D., and Wray, J.J. (2014) A new analysis of Mars "Special Regions": findings of the second MEPAG Special Regions Science Analysis Group (SR-SAG2). Astrobiology 14:887-968.

UN OOSA A/72/20. (2017) Report of the Committee on the Peaceful Uses of Outer Space (COPUOS $60^{\text {th }}$ Session), para 332. United Nations, New York.

Address correspondence to:
J.D. Rummel
SETI Institute
189 Bernardo Ave. Suite 200
Mountain View, CA 94043
E-mail: jrummel@ seti.org
Submitted 22 August 2017
Accepted 29 August 2017

\section{Abbreviations Used}

COSPAR $=$ Committee on Space Research $\mathrm{RSL}=$ recurring slope lineae 